\title{
Developing a High-speed Imaging Set-up for Small Herbaria: a case study from a national herbarium of Nepal (KATH)
}

\author{
Sally King ${ }^{\ddagger}$, Bhaskar Adhikari ${ }^{\ddagger}$, Pratikshya Chalise ${ }^{\S}$, Sajita Dhakal ${ }^{\S}$, Til Kumari Thapa ${ }^{\S}$ \\ ‡ Royal Botanic Garden Edinburgh, Edinburgh, United Kingdom \\ $\S$ National Herbarium \& Plant Laboratories (KATH), Kathmandu, Nepal
}

Corresponding author: Sally King (sking@rbge.org.uk)

Received: 11 Jun 2019| Published: 13 Jun 2019

Citation: King S, Adhikari B, Chalise P, Dhakal S, Thapa T (2019) Developing a High-speed Imaging Set-up for Small Herbaria: a case study from a national herbarium of Nepal (KATH). Biodiversity Information Science and Standards 3: e37095. https://doi.org/10.3897/biss.3.37095

\begin{abstract}
The Himalayan region is recognised as one of the 'hottest' global Biodiversity hotspots, with a third of all species within its range occurring in Nepal. The documentation of the Flora of Nepal is therefore of great importance both nationally and internationally (National Herbarium \& Plant Laboratories (KATH) 2019).

The Royal Botanic Garden Edinburgh (RBGE) leads the Flora of Nepal project in collaboration with the Department of Plant Resources (DPR, part of the Ministry of Forests and Environment), Nepal Academy of Science and Technology (NAST), Central Department of Botany, Tribhuvan University (CDB-TU) and the Society of Himalayan Botany, Tokyo (SHB) (Royal Botanic Gardens Edinburgh 2014).

The National Herbarium and Plant Laboratories (KATH), Kathmandu, Nepal - part of DPR - contains approximately 165,000 herbarium specimens, representing 50\% of vascular plant species and $25 \%$ of lower plant species known to exist in Nepal. The digitisation of herbarium specimens held at KATH will facilitate access to specimen data, expedite the flora writing process, and make it possible to update species distributions to inform conservation priorities.
\end{abstract}


The existing rate of digitisation was slow with 70-75 specimens being fully digitised a day by three digitisers. Specimen collection labels were fully databased in a Microsoft Access database and imaged at $600 \mathrm{PPI}$ using a single Herbscan. At the current rate of digitisation it will take $7-8$ years to completely digitise the KATH herbarium.

As part of the Darwin Initiative project: Science-based interventions reversing negative impacts of invasive plants in Nepal (http://www.darwininitiative.org.uk/project/23031), a new camera imaging set-up and workflow was devised at RBGE, with installation and staff training provided on-site at KATH herbarium (Fig. 1). This has almost tripled the rate of digitisation to $180-200$ specimens per day.

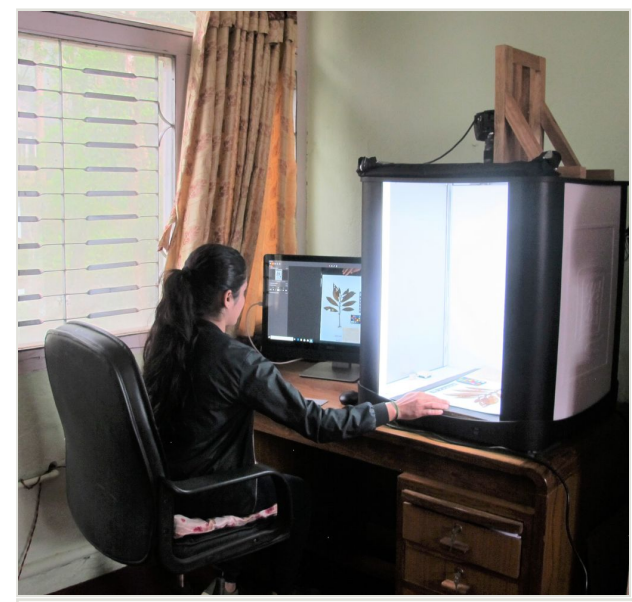

Figure 1.

A digitiser at KATH using the new camera imaging workstation.

The decision making processes that took place regarding hardware and software are discussed including: speed versus quality, some on-site considerations, the installation process and the proposals put forward to further improve the rate of digitisation.

\section{Keywords}

digitisation, herbaria, capacity building, imaging, Nepal, KATH, RBGE, Himalayan, camera

\section{Presenting author}

Sally King 


\section{Presented at}

Biodiversity_Next 2019

\section{References}

- National Herbarium \& Plant Laboratories (KATH) (2019) Flora of Nepal. https://kath.gov.np/ Flora of Nepal. Accessed on: 2019-4-15.

- Royal Botanic Gardens Edinburgh (2014) Flora of Nepal. http://www.floraofnepal.org/. Accessed on: 2019-4-15. 